\title{
Evaluation of precipitation and river discharge variations over southwestern Iran during recent decades
}

\author{
Azadeh Arbabi Sabzevari ${ }^{1, *}$, Mohammad ZarenistanaK ${ }^{2}$, \\ Hossein TABARI ${ }^{3}$ and Shokat Moghimi ${ }^{4}$ \\ ${ }^{1}$ Department of Geography, Islamshahr Branch, Islamic Azad University, Tehran, Iran. \\ ${ }^{2}$ Research Institute of Shakes Pajouh, Isfahan, Iran. \\ ${ }^{3}$ Hydraulics Division, Department of Civil Engineering, KU Leuven, Kasteelpark Arenberg 40, \\ BE-3001 Leuven, Belgium. \\ ${ }^{4}$ Department of Geography, Central Tehran Branch, Islamic Azad University, Tehran, Iran. \\ ${ }^{*}$ Corresponding author. e-mail: zarenistanak@gmail.com
}

This study investigates trend and change point in the annual and monthly precipitation and river discharge time series for a 56-year period (1956/57-2011/12). The analyses were carried out for 17 rain gauge stations and 13 hydrometric stations located in the southwest regions of Iran. Five statistical tests of Mann-Kendall, Spearman, Sequential Mann-Kendall, Pettitt and Sen's slope estimator were utilized for the analysis. The relationships between the precipitation and river discharge series were also examined by the Pearson correlation test. The results obtained for the precipitation time series indicated that most of the stations were characterized by insignificant trends for both the annual and monthly series. The analysis of discharge trends revealed a significant increase during both the annual and October through April series. The magnitude of significant increasing trends in annual river discharge ranged between 6.65 and $20.49 \mathrm{~m}^{3} / \mathrm{s}$ per decade. The highest number of significant trends in the monthly river discharge series was observed in January and February, accounting for seven and four trends respectively. Furthermore, most of the annual and monthly river discharge series showed significant change points in the 1970s. It was also found that river discharge was strongly correlated with precipitation at the annual scale and for most of the months.

\section{Introduction}

The hydrological cycle and thereby available water resources and natural ecosystems have already been documented as having been affected by climate change (Oki and Kanae 2006). Among the hydrological cycle components, river discharge and precipitation variables have received much attention for trend analysis from the scientific community over the last decades because of their significant role in water resources (Masih et al. 2011). Recent researches indicated that the climate change in the southwest of Iran is basically characterized by a significant increase of temperature along with insignificant trends in precipitation (Tabari et al. 2011a; Moazed et al. 2012; Zarenistanak et al. 2014a, b; Dhorde et al. 2014).

So far, many studies have been carried out on the analysis of river discharge and precipitation variability throughout the world (Xiong and Guo 2004; Yang et al. 2005, 2007; Pavelsky and Smith 2006; Cao et al. 2006; Ding et al. 2007; Xu et al. 2010; Du et al. 2011).

Keywords. Change point; correlation; precipitation; river flow; time scale; trend analysis. 
Kahya and Kalayci (2004) found a decreasing trend of stream-flow for the basins located in western Turkey, whereas the basins located in the eastern part showed no trend. Jiang et al. (2007a, b) reported a significant increasing trend in summer precipitation at many stations in the Yangtze River basin in China and a significant increasing trend in river discharge in the middle and lower regions of the basin. In the Euphrates Basin in Turkey, Yenigun et al. (2008) observed a higher number of significant decreasing trends in minimum streamflow compared with significant decreasing ones. While no trend was found for annual maximum stream-flow in the basin, one decreasing trend was obtained for annual mean stream-flow. Feng et al. (2011) found significant increasing trends in annual and seasonal temperature in the Nenjiang River Basin, northeastern China, whereas annual and seasonal precipitation in the basin did not show any significant trend. In addition, a significant decreasing trend in annual, spring and autumn stream-flow was demonstrated. Kriauciuniene et al. (2012) evaluated trends in temperature, precipitation and river discharge over the Baltic States and showed an increase in annual and seasonal temperature in all regions of the Baltic States. They also found an increasing trend for winter precipitation and a decreasing one for spring, summer and autumn series. Winter discharge series increased by $20 \%-60 \%$ in all regions, whereas spring discharge decreased by $10 \%-20 \%$ in western region.

In the north of Iran, Arami et al. (2013) found decreasing trends in annual and seasonal discharge at most stations. In another study, the decreasing trends in low flows in the Karkheh River Basin in the west of Iran were related to a decline in April and May precipitation while increases in the river flood regime were attributed by the increase in winter (particularly March) precipitation along with temperature changes (Masih et al. 2011).

Research on precipitation trends was carried out by the following Iranian scientists: Tabari and Hosseinzadeh Talaee (2011a) examined the temporal trends of precipitation at 41 stations in Iran for the period of 1966-2005. The results showed a significant decreasing trend in annual precipitation series at seven stations. In addition, the number of significant trends in the winter season was higher than that in the other seasons. Shifteh Some'e et al. (2012) reported a noticeable decrease in winter precipitation in northern Iran, as well as along the coasts of the Caspian Sea. On the other hand, Delju et al. (2013) found an increase of $9.2 \%$ in annual precipitation at the Lake Urmia basin from 1966 to 2005. Zarenistanak et al. (2014b) found insignificant increasing trends in annual and seasonal precipitation series at most of the stations located in the southwest of Iran.
Although in Iran some studies have been performed for precipitation (e.g., Boroujerdy 2008; Tabari and Aghajanloo 2013; Dhorde et al. 2014; Zarenistanak et al. 2014b) and river discharge trend analysis (e.g., Naddafi et al. 2007; Ramazanipour 2011; Marofi and Tabari 2012; Niazi et al. 2014), but there are few studies examining trends in both discharge and precipitation series and the relationships between them. As river discharge and precipitation are two critical components of the hydrological cycle, their time series examination is useful in understanding of climatic variation impact on water resources over a given area. The main objective of the present study is to detect trends and change points in the annual and monthly precipitation and discharge time series during the period 1956/57-2011/12 over the southwestern region of Iran. In addition, a correlation analysis was carried out to explore the connection between river discharge and precipitation changes. The results of this study on the identification of long-term precipitation and discharge trends are of great importance in order to make policy decisions in different fields such as agriculture, water supplies, and industry.

\section{Study region and data}

The study region with an area of approximately $60,875 \mathrm{~km}^{2}$ covers the southwestern part of Iran (figure 1a), particularly the provinces of Chaharmahal and Bakhtiari, Kohgiluyeh and BoyerAhmad, and Lorestan (figure 1b). Most of the study region is located amidst the Zagros Mountains and its elevation ranges from $700 \mathrm{~m}$ in the southwest of the Kohgiluyeh and Boyer-Ahmad province to over $4430 \mathrm{~m}$ in the Dena Mountain. The Zagros Mountains are responsible for a major portion of the rain-producing air masses that enter the region from the west and northwest with relatively high amounts of rainfall (Sadeghi et al. 2002). The mean monthly temperature in the region ranges from $-5.8^{\circ} \mathrm{C}$ in January to $23^{\circ} \mathrm{C}$ in July, with an annual mean of $10.2^{\circ} \mathrm{C}$. The mean annual precipitation is $531 \mathrm{~mm}$ that mostly falls during the wet season (winter and autumn) due to the prevalence of humid westerly winds of Mediterranean origin (Zarenistanak 2014). About 30\% of the precipitation is in the form of snow, and the rest is rain and other forms of precipitation (Mousavi 2005). The study region is the most important region of Iran with respect to surface water storage. There are major rivers in the region, such as Karoon, Dez, Kashkan, Seymareh, Maroon, and Zaiande Rood that are generally fed by the snow accumulation of the mountains and the rainfall of the wet season. The river water is transported by canals 

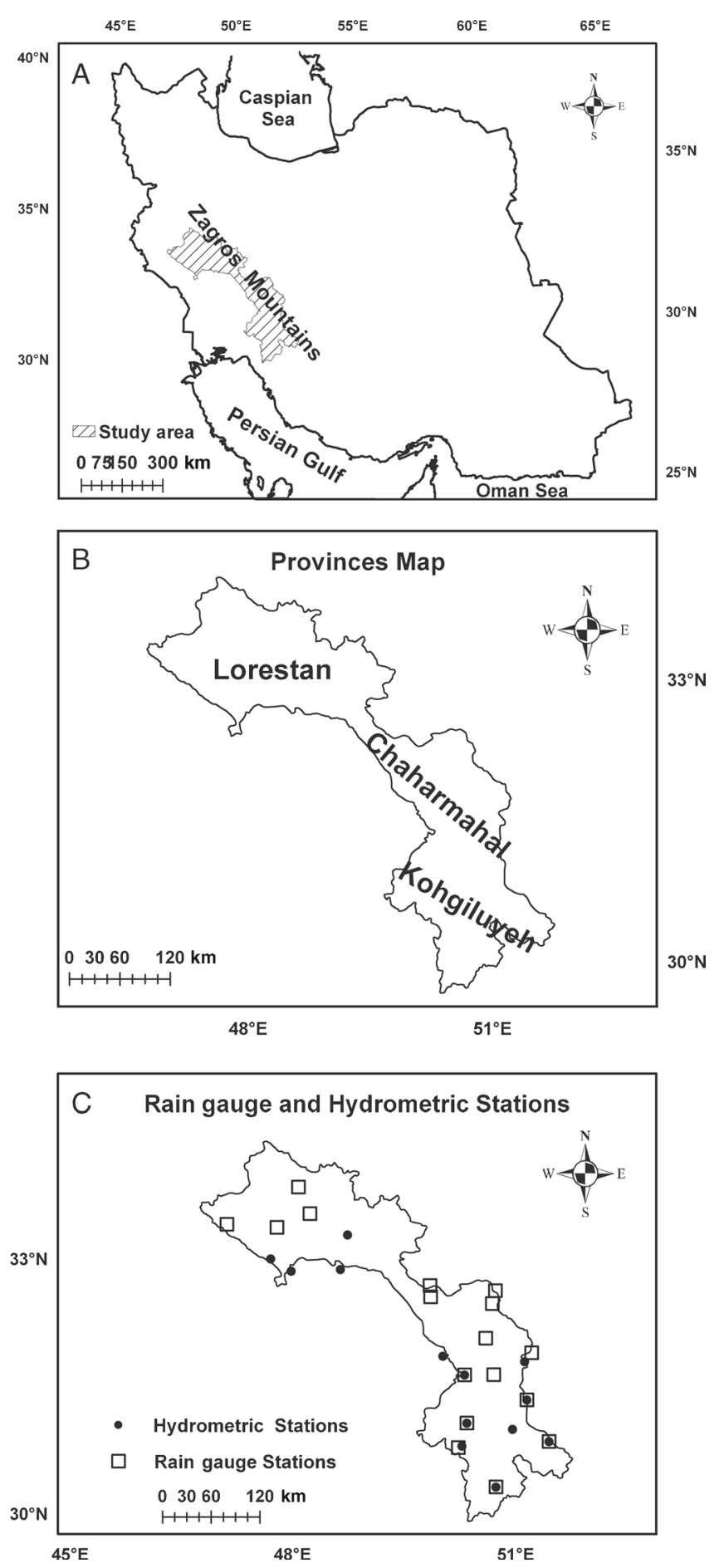

Figure 1. Spatial distribution of the stations in the study area.

from this region to the central arid regions of the country, which face a critical water shortage.

Observed monthly precipitation and discharge data for the period 1956/57-2011/12, obtained from Islamic Republic of Iran Meteorological Organization (IRIMO) and Iranian Water Resources Management Organization were used for this study. The selected stations are fairly evenly spread throughout the study region and have records of at least 33 years. It should be noted that the hydrological year is from October to September of the next year in Iran. The information about the stations is presented in table 1 and the geographical location of the stations is shown in figure 1(c).

The data of the stations were carefully checked for homogeneity and missing values. Missing values were estimated based on correlation analysis between the investigation station and the nearest station in its neighbourhood. The homogeneity of the data was evaluated by a double-mass curve which is a graphical method for identifying or adjusting for inconsistencies in a station record by comparing its time trends with those of other relatively stable records from another station, or an average of several nearby surrounding stations (Kohler 1949). The double-mass curves of all station records are almost a straight line without any obvious breakpoints.

\section{Techniques used}

\subsection{Serial correlation removal from the time series}

One of the problems in the trend analysis of meteorological and hydrological variables is the existence of serial correlation in the time series. It is well-known that serial correlation has a significant impact on the results of trend detection methods like the Mann-Kendall test. In fact, the existence of positive serial correlation will increase the possibility of rejecting the null hypothesis of no trend, while it is actually true (Tabari et al. 2011a). The pre-whitened test is one of the widely used methods to remove serial correlation from time series (von Storch 1995). This method has been applied in many recent studies to remove serial correlation from meteorological and hydrological series (e.g., Xiong and Guo 2004; Partal and Kahya 2006; $\mathrm{Xu}$ et al. 2010; Masih et al. 2011; Tabari et al. 2011a; Tabari and Hosseinzadeh Talaee 2011b; Zarenistanak et al. 2014a).

The general procedure used in this study for detecting trends in the river discharge and precipitation series $\left(\mathrm{x}_{1}, \mathrm{x}_{2}, \mathrm{x}_{3}, \ldots, \mathrm{x}_{\mathrm{n}}\right)$ can be described in two steps:

Step 1: The lag-1 serial correlation coefficient $\left(\mathrm{r}_{1}\right)$ is calculated.

Step 2: If the calculated $r_{1}$ is not significant at the $5 \%$ level, the statistical tests are applied to original time series data. Otherwise, the pre-whitened test $\left(\mathrm{x}_{2}-\mathrm{r}_{1} \mathrm{x}_{1}, \mathrm{x}_{3}-\mathrm{r}_{1} \mathrm{x}_{2}, \ldots, \mathrm{x}_{\mathrm{n}}-\mathrm{r}_{1} \mathrm{x}_{\mathrm{n}-1}\right)$ is used before applying statistical tests (Partal and Kahya 2006).

\subsection{Methods used for trend detection}

In the current study, the trend analysis was carried out by using the Mann-Kendall test (MK-test) 
Table 1. Geographic information of the stations used in the study along with availability (*) of discharge and precipitation data.

\begin{tabular}{|c|c|c|c|c|c|c|}
\hline Station & $\begin{array}{l}\text { Latitude } \\
\qquad(\mathrm{N})\end{array}$ & $\begin{array}{l}\text { Longitude } \\
\text { (E) }\end{array}$ & $\begin{array}{l}\text { Altitude } \\
(\mathrm{m} \text { a.s.l) }\end{array}$ & $\begin{array}{l}\text { Length of } \\
\text { recorded period }\end{array}$ & Discharge & Precipitation \\
\hline Agh Mal & $32^{\circ} 58^{\prime}$ & $50^{\circ} 00^{\prime}$ & 1100 & 33 & & $*$ \\
\hline Barez & $31^{\circ} 52^{\prime}$ & $50^{\circ} 42^{\prime}$ & 825 & 55 & $*$ & $*$ \\
\hline Batari & $30^{\circ} 85^{\prime}$ & $51^{\circ} 03^{\prime}$ & 1520 & 45 & $*$ & \\
\hline Behbahan & $30^{\circ} 66^{\prime}$ & $50^{\circ} 28^{\prime}$ & 333 & 42 & & $*$ \\
\hline Bi Bi Jan Abbad & $30^{\circ} 18^{\prime}$ & $50^{\circ} 76^{\prime}$ & 400 & 43 & $*$ & $*$ \\
\hline Chelgard & $32^{\circ} 45^{\prime}$ & $50^{\circ} 00^{\prime}$ & 2400 & 42 & & $*$ \\
\hline Emam Gheis & $31^{\circ} 73^{\prime}$ & $51^{\circ} 35^{\prime}$ & 2195 & 45 & & $*$ \\
\hline Endack & $30^{\circ} 95^{\prime}$ & $50^{\circ} 42^{\prime}$ & 560 & 45 & $*$ & $*$ \\
\hline Jolow Gir & $32^{\circ} 97^{\prime}$ & $47^{\circ} 80^{\prime}$ & 450 & 55 & $*$ & \\
\hline Kashkan Afrineh & $33^{\circ} 33^{\prime}$ & $47^{\circ} 90^{\prime}$ & 820 & 43 & & $*$ \\
\hline Keta & $31^{\circ} 18^{\prime}$ & $51^{\circ} 25^{\prime}$ & 1600 & 42 & $*$ & $*$ \\
\hline Khorremebad & $33^{\circ} 48^{\prime}$ & $48^{\circ} 36^{\prime}$ & 1125 & 56 & & $*$ \\
\hline Lordegan & $31^{\circ} 50^{\prime}$ & $50^{\circ} 81^{\prime}$ & 1580 & 40 & & $*$ \\
\hline Naghan & $31^{\circ} 93^{\prime}$ & $50^{\circ} 73^{\prime}$ & 2400 & 44 & & $*$ \\
\hline Pang Tang & $32^{\circ} 93^{\prime}$ & $48^{\circ} 77^{\prime}$ & 540 & 56 & * & \\
\hline Pol Zamankhan & $32^{\circ} 48^{\prime}$ & $50^{\circ} 90^{\prime}$ & 1810 & 47 & & $*$ \\
\hline Poole-e-Shalow & $31^{\circ} 75^{\prime}$ & $50^{\circ} 13^{\prime}$ & 700 & 54 & $*$ & \\
\hline Pool-e-Zal & $32^{\circ} 82^{\prime}$ & $48^{\circ} 08^{\prime}$ & 335 & 42 & $*$ & \\
\hline Sarabe Seyed Ali & $33^{\circ} 80^{\prime}$ & $48^{\circ} 21^{\prime}$ & 1520 & 43 & & $*$ \\
\hline Sepiyed Dasht-e-Sezar & $33^{\circ} 22^{\prime}$ & $48^{\circ} 88^{\prime}$ & 970 & 56 & $*$ & \\
\hline Shah Mokhtar & $30^{\circ} 68^{\prime}$ & $51^{\circ} 52^{\prime}$ & 1730 & 45 & $*$ & $*$ \\
\hline Shahrekord & $32^{\circ} 33^{\prime}$ & $50^{\circ} 85^{\prime}$ & 2061 & 53 & & $*$ \\
\hline Solgaun & $31^{\circ} 63^{\prime}$ & $51^{\circ} 25^{\prime}$ & 2150 & 36 & $*$ & \\
\hline Talleh Zang & $32^{\circ} 76^{\prime}$ & $50^{\circ} 63^{\prime}$ & 2100 & 52 & $*$ & \\
\hline Tangeh Seayab & $33^{\circ} 38^{\prime}$ & $47^{\circ} 20^{\prime}$ & 880 & 39 & & $*$ \\
\hline
\end{tabular}

and Spearman's rank test. The Pettitt and Sequential Mann-Kendall (SQ-MK) tests were also used to determine the approximate beginning year of significant trends, and the Sen's slope estimator to estimate trend magnitudes. The results of all methods were tested at $95 \%$ confidence level. Brief explanations of these methods are as follows:

\subsubsection{Mann-Kendall rank test}

The MK-test is one of the most widely used non-parametric tests to detect significant trends in climatic and hydrological time series (e.g., Cao et al. 2006; Partal and Kahya 2006; Jiang et al. 2007a, b; Modarres and da Silva 2007; Tabari and Hosseinzadeh Talaee 2011a, b; Tabari et al. 2011a, b; Zarenistanak et al. 2014a, b).

In this test, only the relative values of all terms in the series $X_{i}$ are used. Therefore, the first step is to replace the $X_{i}$ values by their ranks $k_{i}$, such that each value is assigned a number ranging from 1 to $N$.

The second step includes the computation of the statistic $P$ as follows:

- Compare the rank $\left(k_{1}\right)$ of the first value with those of the later values from the second to the $N$ th value.
- Count the number of later values whose rank exceeds $k_{i}$, and denote this number by $n_{1}$.

- Compare the rank of the second value $\left(k_{2}\right)$ with those of the later values, count the number of later values that exceed $k_{2}$ and denote this by $n_{2}$. Continue this procedure for each value of time series ending with $k_{N-1}$ and its corresponding number $n_{N-1}$.

Now $P$ can be computed by the following equation:

$$
P=\sum_{i=1}^{N-1} n_{i} .
$$

The next step involves computation of the statistic $\tau$ as follows:

$$
\tau=\frac{4 P}{N(N-1)}-1
$$

The value of the $\tau$ statistic can be used as the basis of a significance test by comparing it with:

$$
(\tau)_{t}=0 \pm t_{g} \sqrt{\frac{4 N+10}{9 N(N-1)}}
$$


where $t_{g}$ is the desired probability point of the Gaussian normal distribution. In the present study, $t_{g}$ at 0.05 point has been taken for comparison.

\subsubsection{Spearman rank test}

The Spearman's rank test is a non-parametric rank-order test. In this test, there is a significant trend only if the correlation between time steps and meteorological and hydrological time series is found to be significant (Kahya and Kalayci 2004). The distribution of the Spearman $r_{s}$ statistic will be normal when sample size $n$ is larger than 30 and the $z$ statistic can be used:

$$
z=r_{s} \sqrt{n-1} \text {. }
$$

The positive and negative values of the $z$ statistic indicate increasing and decreasing trends, respectively. If $|z|$ is greater than 1.96 (threshold value of a $95 \%$ confidence level), the null hypothesis of no trend is rejected and there is a significant trend.

\subsubsection{Pettitt test}

The Pettitt test (Pettitt 1979), which is an approximation for a sequence of random variables of the non-parametric method, is used to identify change point in time series (Sneyers 1990; Tarhule and Woo 1998; Smadi and Zghoul 2006; Moazed et al. 2012). One of the reasons for using this test is that it is more sensitive to breaks in the middle of a time series (Wijngaard et al. 2003). The Pettitt test statistic has been explained in several studies (e.g., Kang and Yusof 2012; Dhorde and Zarenistanak 2013; Zarenistanak et al. 2014b). So, the computation procedure of this test is briefly described below.

The $U_{k}$ statistic is initially calculated:

$$
U_{k}=2 \sum_{i=0}^{n} m_{i}-k(n+1)
$$

where $m_{i}$ is the rank of the $i$ th observation when the values $x_{1}, x_{2}, \ldots, x_{n}$ in the series are sorted in ascending order and $k$ takes values from $1,2, \ldots, n$.

The statistical change point test is then defined as:

$$
K=\max _{1 \leq k \leq n}\left|U_{k}\right|
$$

When $U_{k}$ attains maximum value of $K$ in a series, then a change point will occur in the series. The critical value is obtained as follows:

$$
K_{\alpha}=\left[-\ln \alpha\left(n^{3}+n^{2}\right) / 6\right]^{1 / 2}
$$

where $n$ is the number of observations and $\alpha$ is the significance level which determines the critical value.

\subsubsection{Sequential Mann-Kendall test (SQ-MK)}

To detect the change point or the approximate beginning year of significant trends, the non-parametric SQ-MK (Sneyers 1990) was also employed. This test sets up two series, a progressive one $u(t)$ and a backward one $u^{\prime}(t)$. If they cross each other, and then diverge and acquire specific threshold values ( \pm 1.96 for the $95 \%$ confidence level), then there is a statistically significant trend. Herein, $u(t)$ is a standardized variable that has zero mean and unit standard deviation. Therefore, its sequential behaviour fluctuates around the level zero. $u^{\prime}(t)$ is the same as the $z$ values that are found from the first to last data point. This test considers the relative values of all terms in the time series $\left(x_{1}, x_{2}, \ldots, x_{n}\right)$. The test's statistics are computed as follows:

- The magnitudes of $x_{j}$ annual mean time series $(j=1, \ldots, n)$ are compared with $x_{k},(k=1, \ldots$, $j-1)$ and the number of cases $x_{j}>x_{k}$ are counted for each comparison and is denoted by $n_{j}$.

- The test statistic $t$ is then calculated as:

$$
t_{j}=\sum_{1}^{j} n_{j} .
$$

The mean and variance of the statistic are given by

$$
\begin{gathered}
e(t)=\frac{n(n-1)}{4} \\
\operatorname{var} t_{j}=\frac{j(j-1)(2 j+5)}{72} .
\end{gathered}
$$

- Finally, the sequential values of statistic $u(t)$ are estimated by the following equation:

$$
u(t)=\frac{t_{j-} e_{(t)}}{\sqrt{\operatorname{var}\left(t_{j}\right)}} .
$$

The values of $u^{\prime}(t)$ are calculated backward similar to $u(t)$, but starting from the end of the series. The sequential version of the MK-test could be considered as an effective way of locating the beginning year of a trend. The intersection of the forward and backward curves indicated the time when a trend or change starts.

\subsubsection{Sen's slope estimator}

The Sen's slope estimator method was used to determine the magnitude of the long-term trends in river discharge and precipitation. With an assumed linear trend in time series, the slope (change per unit time) of trends can be estimated by using a simple non-parametric procedure proposed by Sen (1968). Recently, most of the studies used the 
Sen's slope estimator method instead of a linear regression for estimating trend slope in meteorological and hydrological time series (e.g., Partal and Kahya 2006; Zarenistanak 2008; Abghari et al. 2013).
The Sen's slope estimates of $N$ pairs of data are first computed by

$$
Q_{i}=\frac{x_{j}-x_{k}}{j-k} \quad \text { for } i=1, \ldots, N
$$

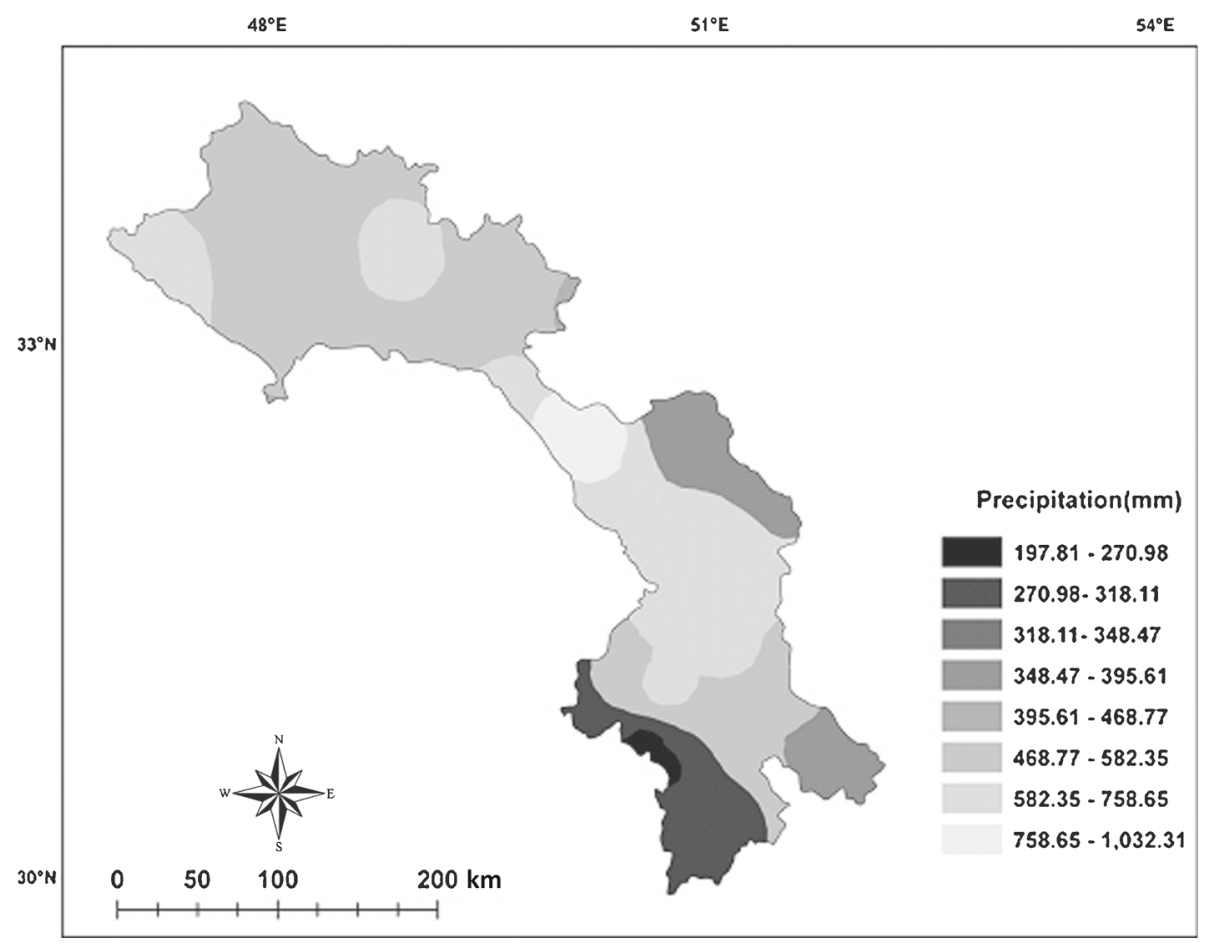

Figure 2. Annual rainfall zones.

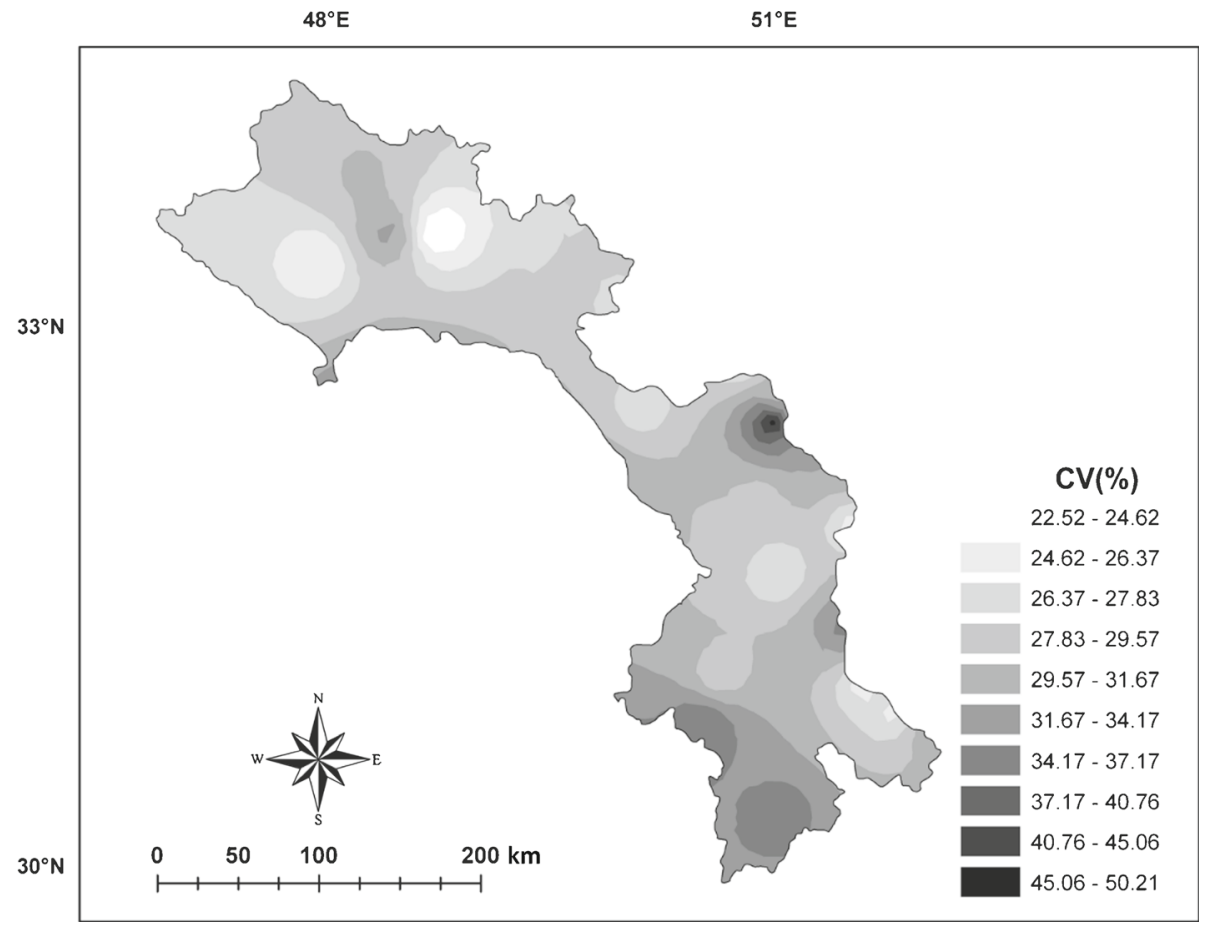

Figure 3. Spatial pattern of coefficient of variation $(\mathrm{CV})$ of annual precipitation. 
where $x_{j}$ and $x_{k}$ are data values at times $j$ and $k$ $(j>k)$, respectively. The median of these $N$ values of $Q_{i}$ is Sen's estimator of slope. If $N$ is odd, then Sen's estimator is computed by

$$
Q_{\text {med }}=Q_{(N+1) / 2} \text {. }
$$

If $N$ is even, then Sen's estimator is computed by Partal and Kahya (2006)

$$
Q_{\text {med }}=\frac{1}{2}\left(Q_{[N / 2]}+Q_{[(N+2) / 2]} .\right.
$$

The total changes during the period under observation are estimated with multiplying the slope by the number of years (here multiplied by 10 to find the decadal change).

\section{Results and discussion}

The majority of the annual and monthly precipitation and discharge series appears to have no significant lag-1 serial correlation coefficient. The highest number of significant serial correlation was observed in the October and April discharge and precipitation series, respectively. The time series with significant serial correlation at the 0.05 level were subjected to a pre-whitening procedure before applying statistical methods. The non-parametric MK-test and Spearman's rank test were applied to detect trends in the annual and monthly precipitation and discharge series for all selected stations. The spatial distribution maps of the trends identified by the MK-test in the annual and monthly series were prepared. According to the Pettitt and SQ-MK tests, the change points in the annual and monthly precipitation and discharge series were identified to detect the beginning year of the trends. The magnitude of the trends was estimated by applying the Sen's slope estimator method. The trends were considered statistically significant at the 0.05 level when identified by all the statistical methods.

\subsection{Temporal variation of precipitation}

Most precipitation in the Zagros Mountains occurs between October and May after which the warmdry season prevails. Coefficient of variation (CV) was computed for all of the study stations to investigate the spatial pattern of the variability of precipitation over the study area. Annual rainfall zones and annual CV are depicted in figures 2 and 3 , respectively. The annual precipitation variability reveals that Keta station with a $\mathrm{CV}$ of $48 \%$ showed the highest temporal variability, while the lowest CV was found at Chelgard station. Also, Shah Mokhtar and Shahrekord with average annual precipitation values of 980 and $200 \mathrm{~mm}$ had the highest and lowest precipitation amounts, respectively (table 2). Generally, the largest CV values can be seen in the south of the study area where the rainfall amount is low. The results also indicated that January precipitation had the lowest CV compared to the other months, while the August series revealed the largest CV (figure 4). The high variability in precipitation in Iran can be related to synoptic systems and year-to-year variations in different numbers of passing cyclones (Soltani et al. 2011).

According to the results (figure 5), the trend tests did not detect any significant trend in the annual, October, November, January, March, April, May, June, and September precipitation

Table 2. Descriptive statistics of the annual precipitation series.

\begin{tabular}{lccc}
\hline Station & $\begin{array}{c}\text { Mean } \\
(\mathrm{mm})\end{array}$ & $\begin{array}{c}\text { SD } \\
(\mathrm{mm})\end{array}$ & $\begin{array}{c}\text { CV } \\
(\%)\end{array}$ \\
\hline Agh Mal & 800 & 238 & 30 \\
Barez & 656 & 181 & 27 \\
Behbahan & 356 & 155 & 42 \\
Bi Bi Jan Abbad & 350 & 131 & 37 \\
Chelgard & 566 & 131 & 23 \\
Emam Gheis & 588 & 145 & 24 \\
Endack & 652 & 179 & 27 \\
Kashkan Afrineh & 505 & 126 & 24 \\
Keta & 555 & 260 & 48 \\
Khorremebad & 510 & 125 & 25 \\
Lordegan & 527 & 170 & 30 \\
Naghan & 633 & 180 & 28 \\
Pol Zamankhan & 348 & 109 & 31 \\
Sarabe Seyed Ali & 517 & 157 & 30 \\
Shah Mokhtar & 980 & 244 & 28 \\
Shahrekord & 200 & 93 & 46 \\
Tangeh Seayab & 220 & 100 & 41 \\
\hline
\end{tabular}

$\mathrm{SD}=$ standard deviation.

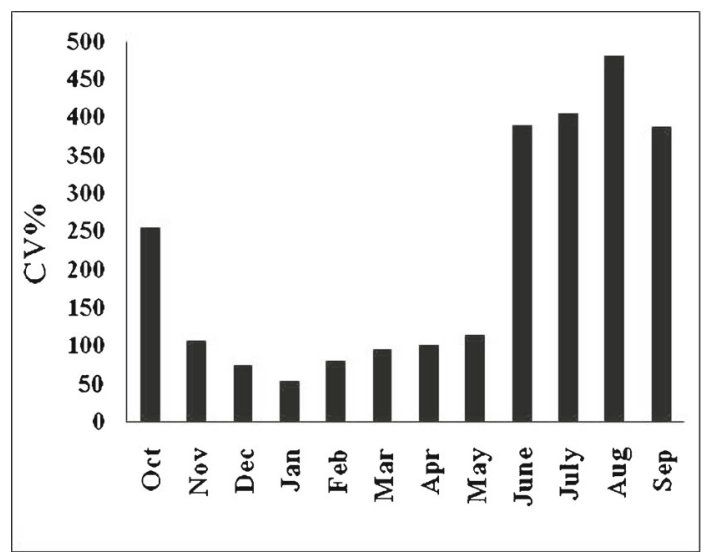

Figure 4. Monthly average of coefficient of variation. 
series. Raziei (2008), Tabari et al. (2011a), Dhorde et al. (2014) and Zarenistanak et al. (2014b) also reported insignificant precipitation trends over the southwest part of Iran. Emam Gheis station situated in the west of the study area indicated significant increasing trends in the December

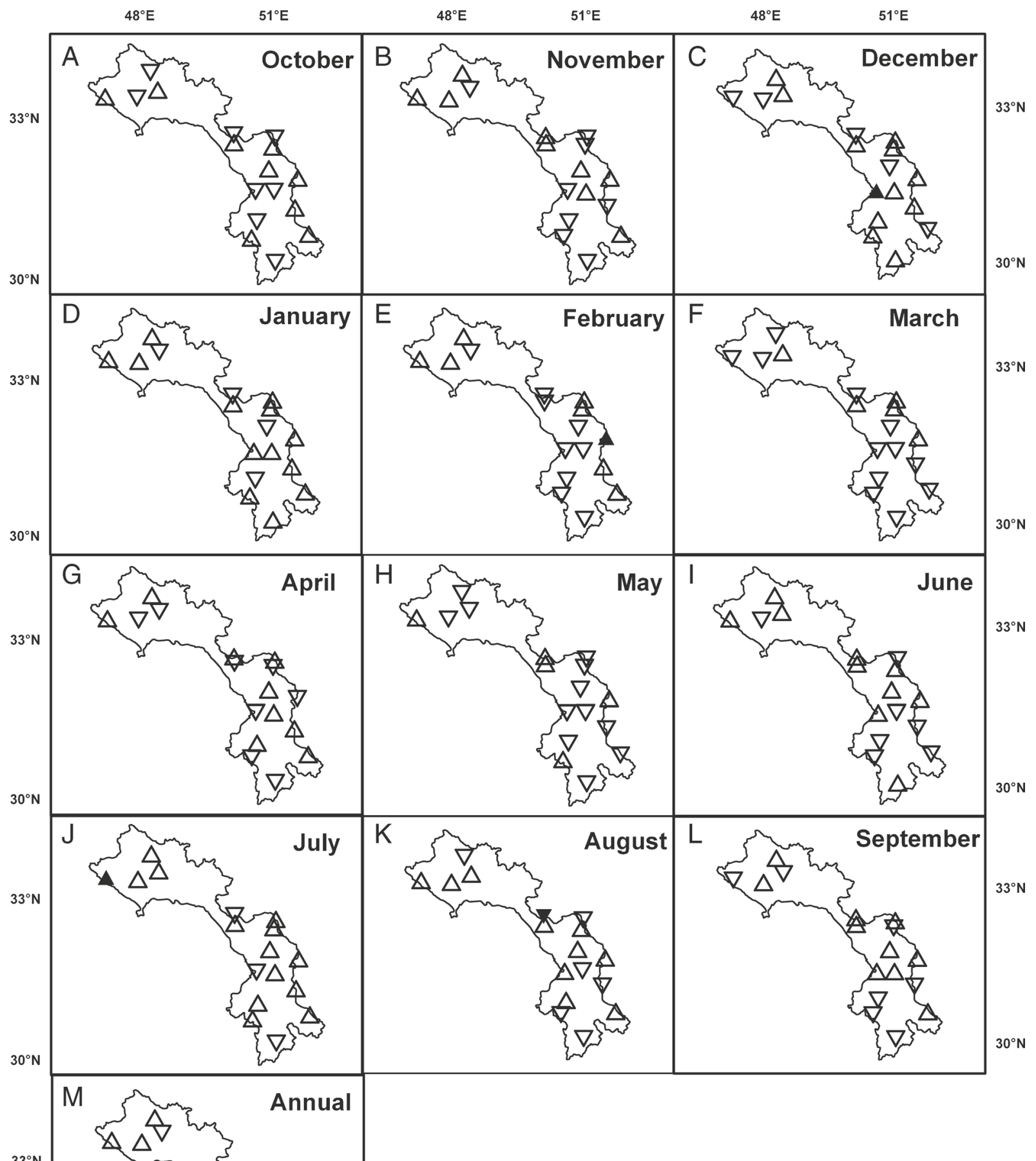

Significant decreasing trend

A Significant increasing trend

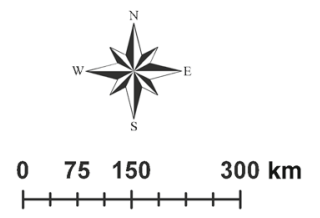

Figure 5. Spatial distribution of the trends in the annual and monthly precipitation series obtained by MK-test. Shaded triangles indicate significant trends at 95\% confidence level. Hollow triangles indicate insignificant trends. 
and February series based on the statistical tests. According to the Sen's slope estimator, the rate of significant precipitation changes were 19.33 and $16.77 \mathrm{~mm} /$ decade in December and February, respectively (table 3 ). Mutation point at this station occurred around 1980-1981 and 1992-1993 in December and February, respectively (figure 6). As plots indicated, the significant increasing trends in December at Emam Gheis station began around 1980/81 and reached a confidence level around 1998/99 (figure 6a) and for the February series, it started around the hydrological year 1992/93 and acquired the specific threshold value of 1.96 in 2000/01 (figure 6b).

Figure 5 presents the spatial pattern of the trends obtained by applying the MK-test in the annual and monthly precipitation series. The pattern of the precipitation trends were not generally uniform over the Zagros Mountains and there were various patterns. The results of the Spearman's rho test for the annual and monthly precipitation time series confirmed the trends obtained by the MK-test (table 4). Shifteh Somee et al. (2012) observed insignificant trends in annual and

Table 3. Values of the Sen's slope estimator (mm/decade) for the annual and monthly precipitation time series (1956/572011/12).

\begin{tabular}{|c|c|c|c|c|c|c|c|c|c|c|c|c|c|}
\hline Station & Oct & Nov & Dec & Jan & Feb & Mar & Apr & May & Jun & Jul & Aug & Sep & Annual \\
\hline Agh Mal & 0.00 & -0.95 & 8.64 & -1.25 & -20.00 & -24.00 & 11.88 & 1.15 & 0.00 & 0.00 & 0.00 & 0.00 & -54.00 \\
\hline Barez & 0.00 & 0.00 & 1.67 & 10.88 & -5.10 & -16.45 & 1.46 & -0.77 & 0.00 & 0.00 & 0.00 & 0.00 & 48.33 \\
\hline Behbahan & 0.00 & -0.39 & 2.63 & 0.55 & -7.40 & -0.14 & -0.55 & 0.00 & 0.00 & 0.00 & 0.00 & 0.00 & -2.00 \\
\hline Bi Bi Jan Abbad & 0.00 & -5.60 & 7.12 & 8.41 & -10.00 & -0.23 & -1.67 & 0.00 & 0.00 & 0.00 & 0.00 & 0.00 & 13.09 \\
\hline Chelgard & 0.00 & 3.33 & -12.00 & 5.94 & -21.54 & -8.50 & 5.42 & -1.05 & 0.00 & 0.00 & 0.00 & 0.00 & -31.25 \\
\hline Emam Gheis & 0.00 & -2.48 & $19.33^{*}$ & 8.50 & $16.77^{*}$ & 3.94 & -6.67 & -3.33 & 0.00 & 0.00 & 0.00 & 0.00 & 32.90 \\
\hline Endack & 0.00 & 1.39 & -3.82 & -0.63 & -8.95 & -2.52 & -2.35 & -2.35 & 0.00 & 0.00 & 0.00 & 0.00 & -4.96 \\
\hline Kashkan Afrineh & 0.00 & 6.67 & -10.77 & 6.36 & 2.73 & -0.50 & 10.00 & -5.25 & 0.00 & 0.00 & 0.00 & 0.00 & 3.33 \\
\hline Keta & 0.00 & 0.00 & 11.67 & -6.52 & 10.77 & -14.22 & 10.00 & 0.00 & 0.00 & 0.00 & 0.00 & 0.00 & 36.29 \\
\hline Khorremebad & 0.00 & -2.80 & 2.19 & -0.31 & -0.12 & 4.15 & -3.44 & -0.93 & 0.00 & 0.00 & 0.00 & 0.00 & -5.63 \\
\hline Lordegan & 0.00 & 2.32 & -4.44 & 5.81 & -5.00 & -4.29 & 1.84 & -2.38 & 0.00 & 0.00 & 0.00 & 0.00 & 19.93 \\
\hline Naghan & 0.00 & -0.98 & 3.78 & -1.10 & -3.75 & -0.67 & -3.69 & -4.12 & 0.00 & 0.00 & 0.00 & 0.00 & -17.94 \\
\hline Pol Zamankhan & 0.00 & 2.44 & 9.07 & 6.29 & 2.50 & 5.47 & -2.52 & -1.15 & 0.00 & 0.00 & 0.00 & 0.00 & 13.59 \\
\hline Sarabe Seyed Ali & 0.00 & 8.10 & -6.64 & 6.35 & 5.17 & -9.13 & 5.27 & -3.64 & 0.00 & 0.00 & 0.00 & 0.00 & 3.64 \\
\hline Shah Mokhtar & 0.00 & 0.00 & 8.00 & 11.15 & 8.18 & -3.54 & 0.00 & -2.68 & 0.00 & 0.00 & 0.00 & 0.00 & 47.29 \\
\hline Shahrekord & 0.00 & 2.70 & 6.13 & 0.45 & 0.88 & 3.51 & -1.13 & -0.14 & 0.00 & 0.00 & 0.00 & 0.00 & 13.59 \\
\hline Tangeh Seayab & 0.00 & 6.67 & 5.29 & 5.11 & 0.00 & -8.58 & 6.85 & 0.00 & 0.00 & 0.00 & 0.00 & 0.00 & 4.77 \\
\hline
\end{tabular}

(*) Trends statistically significant at $95 \%$ confident level.
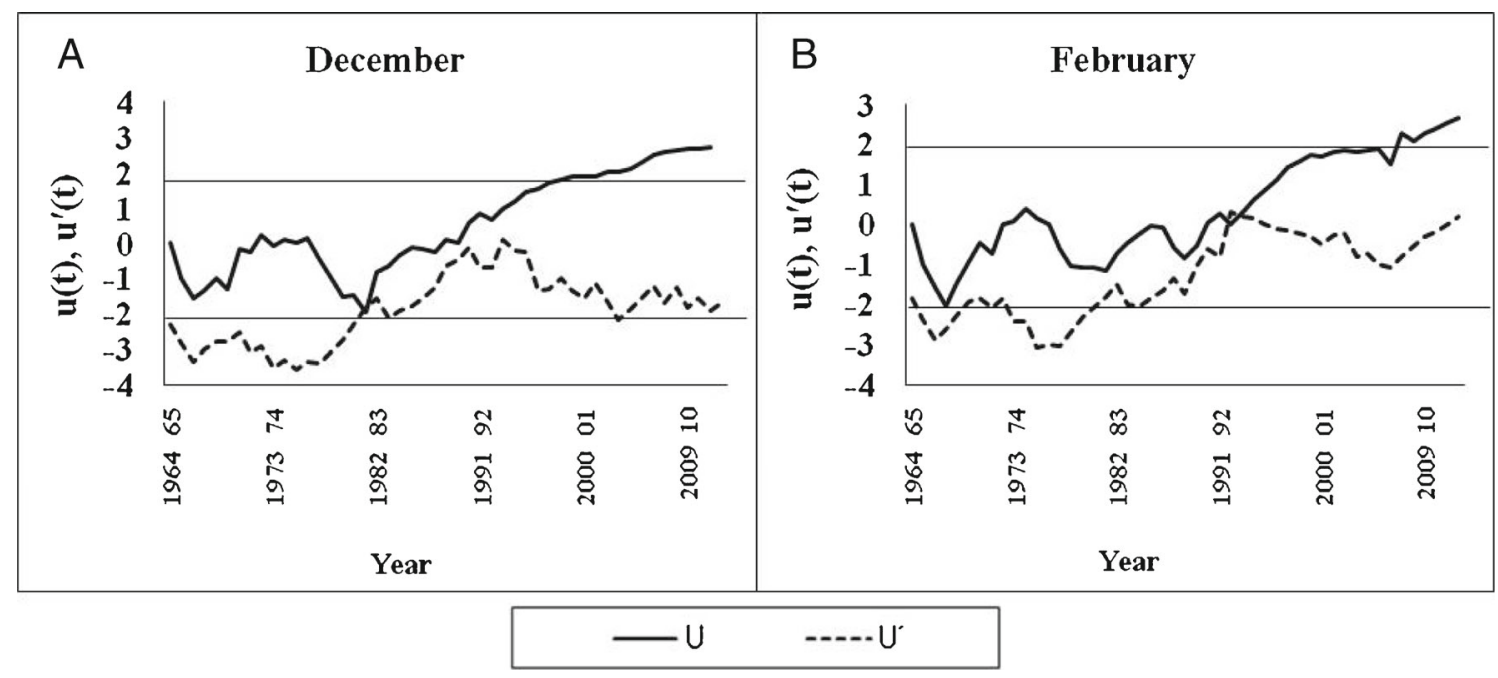

Figure 6. Graphical illustration of the series $u(t)$ and the backward series $u^{\prime}(t)$ of the SQ-MK test for the December and Feburary precipitation series at Emam Gheis station. 
Table 4. Values of the statistic $Z$ of the Spearman's rho test for the annual and monthly precipitation (1956/57-2011/12).

\begin{tabular}{lrrrrrrrrrrrrr}
\hline Station & Oct & Nov & Dec & Jan & Feb & Mar & Apr & May & Jun & Jul & Aug & Sep & Annual \\
\hline Agh Mal & -0.31 & -0.06 & 0.08 & -0.03 & 0.16 & -0.27 & 0.18 & 0.13 & -0.27 & 0.00 & 0.05 & -0.16 & -0.20 \\
Barez & 0.13 & -0.05 & 0.01 & 0.14 & 0.07 & -0.03 & 0.03 & -0.08 & -0.18 & 0.28 & -0.10 & -0.05 & 0.22 \\
Behbahan & 0.04 & -0.04 & 0.06 & 0.02 & -0.22 & -0.03 & -0.03 & 0.09 & 0.06 & 0.00 & 0.00 & -0.08 & 0.00 \\
Bi Bi Jan Abbad & 0.11 & -0.24 & 0.16 & 0.19 & -0.24 & -0.04 & -0.07 & -0.19 & 0.06 & 0.12 & 0.00 & -0.12 & 0.13 \\
Chelgard & -0.02 & 0.11 & -0.18 & 0.09 & -0.32 & -0.20 & 0.11 & -0.21 & 0.00 & -0.31 & $-0.37 *$ & 0.00 & -0.27 \\
Emam Gheis & -0.15 & -0.09 & $0.34^{*}$ & 0.13 & $0.42^{*}$ & 0.12 & 0.14 & -0.31 & 0.13 & -0.06 & 0.10 & 0.05 & 0.25 \\
Endack & -0.12 & 0.11 & -0.10 & 0.05 & -0.16 & -0.05 & -0.03 & -0.02 & -0.18 & 0.21 & 0.07 & 0.21 & 0.00 \\
Kashkan Afrineh & 0.22 & 0.14 & -0.12 & 0.15 & 0.07 & -0.02 & 0.25 & -0.18 & -0.07 & 0.17 & 0.00 & 0.00 & 0.05 \\
Keta & -0.09 & 0.05 & 0.16 & -0.07 & 0.16 & -0.26 & 0.22 & -0.04 & 0.08 & -0.29 & -0.06 & 0.00 & 0.20 \\
Khorremebad & 0.063 & -0.14 & 0.07 & -0.07 & 0.01 & 0.14 & -0.10 & -0.09 & -0.04 & 0.07 & -0.07 & -0.22 & -0.04 \\
Lordegan & 0.059 & 0.08 & -0.11 & 0.12 & -0.09 & -0.12 & 0.06 & -0.08 & 0.10 & $0.33 *$ & 0.09 & -0.05 & 0.11 \\
Naghan & -0.13 & -0.04 & 0.08 & -0.16 & -0.09 & -0.05 & -0.09 & -0.29 & 0.26 & 0.00 & -0.06 & -0.07 & 0.13 \\
Pol Zamankhan & 0.09 & 0.11 & 0.17 & 0.23 & 0.06 & 0.22 & -0.04 & -0.16 & 0.15 & 0.17 & 0.28 & 0.18 & 0.14 \\
Sarabe Seyed Ali & 0.28 & 0.20 & -0.12 & 0.17 & 0.14 & -0.21 & 0.21 & -0.12 & -0.03 & 0.25 & 0.00 & 0.00 & 0.03 \\
Shah Mokhtar & -0.03 & -0.07 & 0.07 & 0.16 & 0.15 & -0.07 & 0.04 & 0.15 & -0.05 & 0.01 & -0.12 & 0.00 & 0.29 \\
Shahrekord & 0.14 & 0.20 & 0.22 & 0.04 & 0.05 & 0.14 & -0.06 & -0.05 & 0.26 & 0.28 & 0.01 & 0.25 & 0.19 \\
Tangeh Seayab & -0.06 & 0.18 & 0.15 & 0.15 & 0.00 & -0.22 & 0.16 & 0.10 & -0.15 & 0.00 & -0.04 & 0.07 & 0.10 \\
\hline
\end{tabular}

(*) Trends statistically significant at $95 \%$ confident level.

seasonal precipitation data at most of the stations in Iran.

\subsection{Temporal variation of river discharge}

To understand the river's discharge regime, the descriptive statistics of annual river discharge at the study stations were computed (table 5). The analysis indicated that Poole-e-Shalow station with an average annual river discharge of $299.81 \mathrm{~m}^{3} / \mathrm{s}$ had the highest annual water yield, whereas the lowest annual water yield was observed at Pool-eZal station. Moreover, the annual river discharge time series at Bi Bi Jan Abbad station with a CV of $54.91 \%$ showed the highest temporal variability. In contrast, the lowest CV of $31.83 \%$ was found at Solgaun station (table 5).

The results of the trend tests on the annual and monthly river discharge series are shown in figure 7 . The results indicated that all of the significant trends in the annual discharge series were found to be increasing (figure $7 \mathrm{M}$ ). The river discharge of Barez, Bi Bi Jan Abbad, Pang Tang, Poole-e-Shalow and Talleh Zang stations increased significantly at a significance level of 0.05 . The magnitudes of the significant trends at the abovementioned stations were 14.03, 12.21, 6.65, 15.57, and $20.49 \mathrm{~m}^{3} / \mathrm{s}$ per decade, respectively (table 6 ). Spatially, the majority of the increasing significant trends in the annual river discharge series were observed in the south of the study area (figure $8 \mathrm{~m}$ ).

The $u(t)$ and $u^{\prime}(t)$ curves of the SQ-MK test for the annual river discharge series at the stations
Table 5. Descriptive statistics of the annual river discharge series at the study stations.

\begin{tabular}{lcc}
\hline Station & $\begin{array}{r}\text { Mean } \\
\left(\mathrm{m}^{3} / \mathrm{s}\right)\end{array}$ & $\begin{array}{c}\mathrm{CV} \\
(\%)\end{array}$ \\
\hline Barez & 113.64 & 41.15 \\
Batari & 18.50 & 40.82 \\
Bi Bi Jan Abbad & 20.45 & 54.91 \\
Endack & 52.79 & 41.25 \\
Jolow Gir & 149.8 & 42.04 \\
Keta & 39.84 & 37.42 \\
Pang Tang & 143.87 & 34.72 \\
Poole-e-Shalow & 299.81 & 43.32 \\
Pool-e-Zal & 9.62 & 36.02 \\
Sepiyed Dasht-e-Sezar & 44.56 & 50.99 \\
Shah Mokhtar & 24.14 & 37.65 \\
Solgaun & 10.01 & 31.83 \\
Talleh Zang & 19.57 & 47.24 \\
\hline
\end{tabular}

with significant trends are shown in figure 9. As the plots indicate, the significant increasing trend of the Barez station began around the hydrological year 1972/73 and reached a confidence greater than $95 \%$ around 1982/83. At Bi Bi Jan Abbad station, the $u(t)$ and $u^{\prime}(t)$ curves cross each other in 1970/71, and then diverge and acquire a specific threshold value of 1.96 in $1983 / 84$. Moreover, the increasing significant trends of annual river discharge at Pang Tang, Poole-e-Shalow and Talleh Zang stations began in the hydrological years 1982/83, 1972/73 and 1970/71 respectively and became significant in the hydrological years $1988 / 89,1982 / 83$ and 1985/86, respectively. 


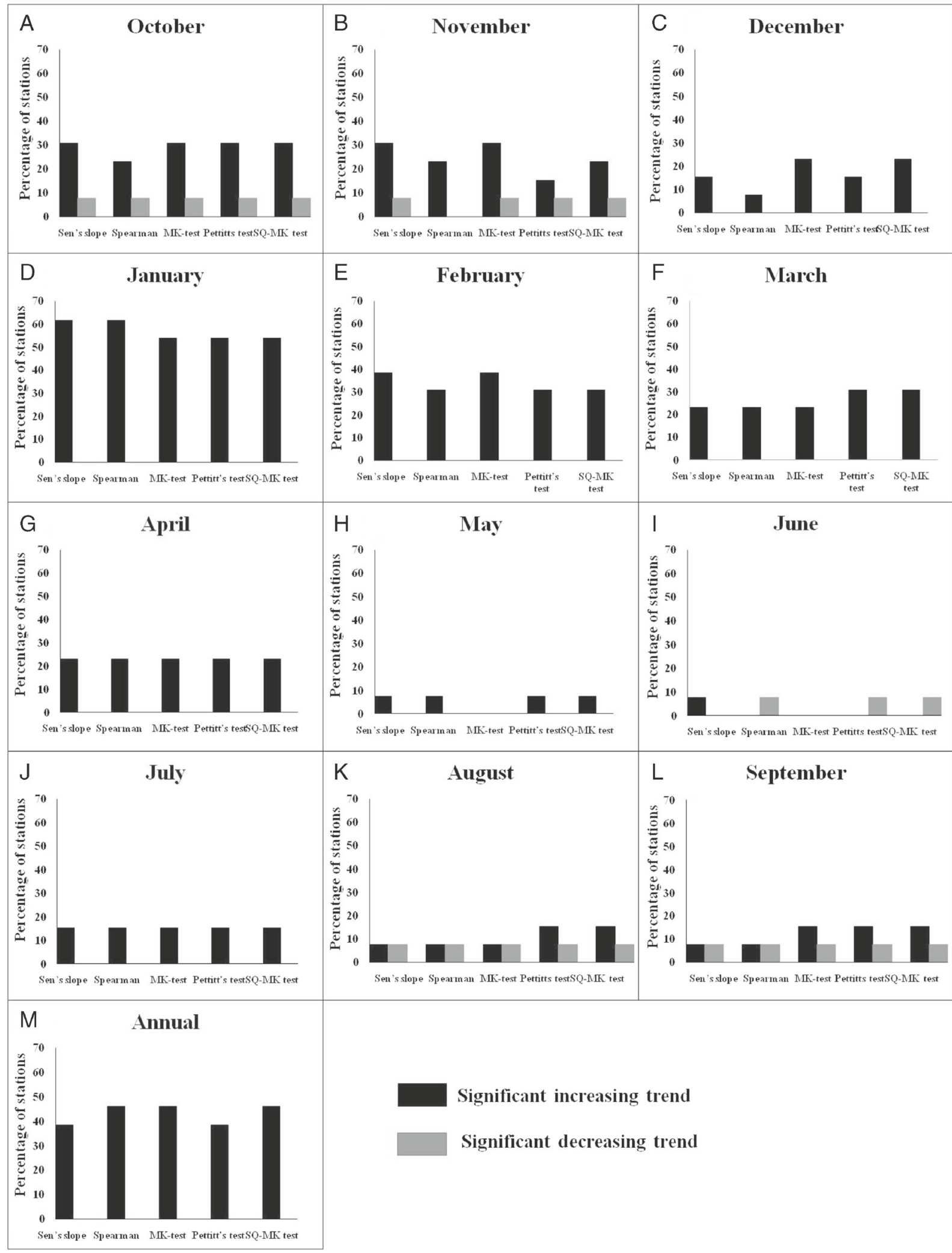

Figure 7. Percentage of stations with significant trends at 95\% confidence level by Sen's slope estimator, Spearman's rank test, MK-test, Pettitt's test and SQ-MK test for the annual and monthly discharge time series.

The results of the Pettitt and the SQ-MK test are summarized in tables 7 and 8 , respectively. Increasing and decreasing trends are represented by $(+)$ and $(-)$ signs respectively; each station is characterized by year, which reflects the initiation of an increasing or decreasing trend. In addition, the $N$ in some stations denotes that there is no significant trend for the study period. The results 
Table 6. Values of the Sen's slope estimator (mm/decade) for the annual and monthly discharge time series (1956/572011/12).

\begin{tabular}{|c|c|c|c|c|c|c|c|c|c|c|c|c|c|}
\hline Station & Oct & Nov & Dec & Jan & Feb & Mar & Apr & May & Jun & Jul & Aug & Sep & Annual \\
\hline Barez & $2.68 *$ & $3.46^{*}$ & $6.45^{*}$ & $16.34^{*}$ & $15.61^{*}$ & $31.02 *$ & k 17.93 & 10.74 & $10.6 *$ & 3.79 & 3.18 & 2.28 & $14.03^{*}$ \\
\hline Batari & 0.05 & 0.01 & -0.60 & 2.80 & 4.00 & 3.84 & 5.21 & 1.36 & 0.20 & 0.17 & -0.06 & -0.05 & 2.09 \\
\hline Bi Bi Jan Abbad & 1.30 & $3.89^{*}$ & 5.39 & $15.26^{*}$ & $21.93 *$ & $19.34 *$ & $24.87 *$ & $7.68^{*}$ & 3.56 & $2.00 *$ & 1.17 & 0.90 & $12.21 *$ \\
\hline Endack & 0.17 & 0.76 & 0.34 & 8.98 & 12.02 & 9.16 & 9.48 & 2.60 & 0.50 & 1.01 & 0.31 & 0.16 & 5.73 \\
\hline Jolow Gir & -1.86 & -0.66 & -1.10 & 0.75 & -1.15 & 24.85 & 13.22 & -7.65 & -1.97 & -0.12 & -1.39 & -1.73 & 4.21 \\
\hline Keta & -0.47 & -0.21 & -0.18 & 2.12 & 3.53 & 5.27 & 8.40 & 5.19 & 0.14 & 1.00 & -0.85 & -1.29 & 3.23 \\
\hline Pang Tang & $2.32 *$ & $2.16^{*}$ & 2.41 & $9.01 *$ & $10.49 *$ & 9.12 & 6.30 & 0.28 & 0.89 & $3.89 *$ & $3.27^{*}$ & * $2.99 *$ & $6.65^{*}$ \\
\hline Poole-e-Shalow & $6.01 *$ & 7.80 & $13.53^{*}$ & $32.63^{*}$ & $32.41^{*}$ & $27.29 *$ & $23.02 *$ & 5.80 & 22.21 & 6.41 & 5.8 & 4.01 & $15.57 *$ \\
\hline Pool-e-Zal & 0.11 & 0.31 & 1.88 & 0.93 & -0.75 & -2.88 & -0.43 & -0.11 & -0.38 & -0.28 & -0.04 & -0.008 & -0.10 \\
\hline $\begin{array}{l}\text { Sepiyed Dasht-e- } \\
\text { Sezar }\end{array}$ & 0.25 & 0.06 & 1.77 & $2.35 *$ & 1.92 & 3.52 & 6.58 & 0.68 & -0.26 & 0.08 & 0.009 & 0.001 & 2.33 \\
\hline Shah Mokhtar & $0.56^{*}$ & $0.72^{*}$ & 1.25 & $3.51^{*}$ & $7.25 *$ & 6.69 & 1.97 & 0.11 & 0.15 & 0.38 & 0.50 & 0.67 & 2.69 \\
\hline Solgaun & $-0.80^{*}$ & $-1.25^{*}$ & -1.47 & $-1.40 *$ & -1.17 & -0.24 & -4.63 & -4.23 & -1.16 & -0.70 & $-0.90 *$ & $-0.89 *$ & -1.25 \\
\hline Talleh Zang & 1.62 & 3.75 & 14.13 & $16.08 *$ & 12.63 & 24.63 & $33.06 *$ & 29.08 & 9.96 & 6.11 & 4.46 & 3.52 & $20.49^{*}$ \\
\hline
\end{tabular}

(*)Trends statistically significant at $95 \%$ confident level.

of the Pettitt and SQ-MK tests for the annual and monthly discharge series indicated that the mutation points of the increasing significant trends occurred mostly in the 1970s. According to the Pettitt's test, more than $80 \%$ of the increasing significant mutation points in the discharge series began in 1970s, while $8 \%$ of them occurred in 1980s (table 7). However, the results of the SQ-MK test showed that $73 \%$ of the increasing significant mutation points occurred during 1970s and 1980s, and $20 \%$ in 1980 s (table 8 ).

According to monthly river discharge variations (figure 8), the majority of the river discharge series showed an increasing insignificant trend. The significant increasing trends in monthly river discharge were more evident in the January and February time series compared with the other monthly time series (figure $7 \mathrm{D}$ and $\mathrm{E}$ ). In fact, $56.88 \%$ and $33.78 \%$ of the stations showed a significant increasing trend in January and February, respectively. Inversely, no significant trends were found in May and June. Seasonally, stronger increasing trends in the river discharge series were obtained in the autumn and winter seasons. Among the considered stations, the highest number of significant increasing trends were observed at $\mathrm{Bi}$ Bi Jan Abbad, Pang Tang, and Barez stations, whereas no significant trends were found at Endack and Pool-e-Zal stations. Furthermore, significant decreasing trends were found only at Solgaun station. The magnitudes of monthly river discharge trends are presented in table 6 . One can see that the highest magnitudes of the significant increasing trends in the monthly river discharge time series were found in the January and February series of Poole-e-Shalow station at the rates of 32.63 and $32.41 \mathrm{~m}^{3} / \mathrm{s}$ per decade, respectively. Abghari et al. (2013) found significant decreasing trends in annual river discharge at most of the stations located in the west of Iran. The results of the Spearman's rho test for the annual and monthly discharge time series (table 9) are in accordance to those of the MK-test.

\section{Connection between precipitation and discharge variability}

To investigate the impact of precipitation on river discharge variability, the connection between the two variables was examined. No significant trends were detected in the annual precipitation series, while annual discharge series showed that five stations registered significantly increasing trends, though the number of the discharge stations were less (13) than the precipitation ones (17). At the monthly level, higher number of significant trends were observed in discharge as compared to precipitation. In the discharge series, majority of significant increasing trends occurred in the October through April series, whereas only one station showed significant increasing trends in precipitation during December and February.

The Pearson correlation coefficient (two-tailed) was used to check the relationship between precipitation and river discharge. The correlation coefficients between area-averaged precipitation and river discharge (figure 10) indicated that annual area-averaged river discharge had a significant positive correlation with annual area-averaged 


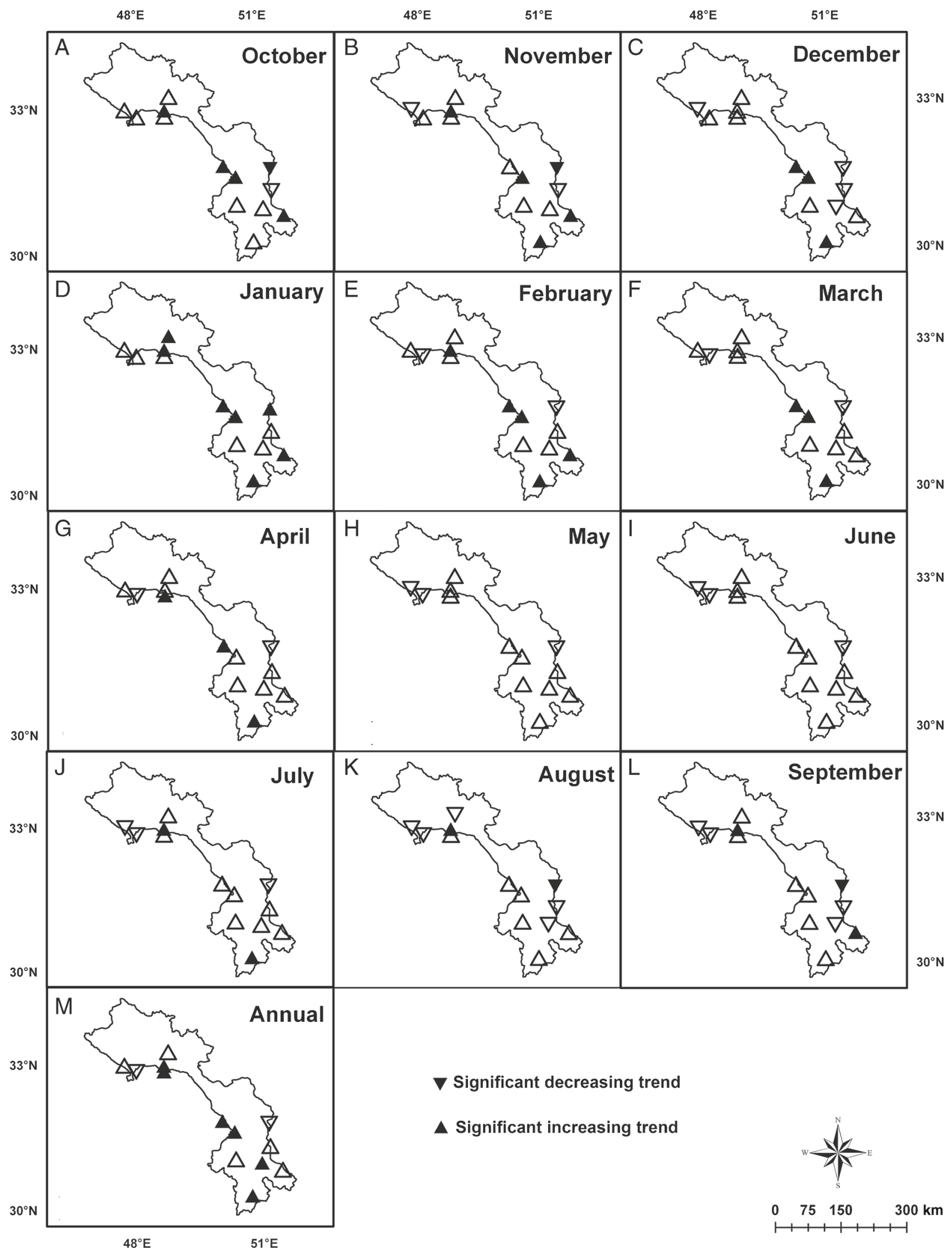

Figure 8. Spatial distribution of the trends in the annual and monthly discharge series obtained by MK-test. Shaded triangles indicate significant trends at $95 \%$ confidence level. Hollow triangles indicate insignificant trends.

precipitation at the significance level of 0.05. Similarly, monthly area-averaged river discharge showed a positive correlation with monthly area-averaged precipitation with the exception of October, July, August, and September. All of the negative correlations between monthly area-averaged river 

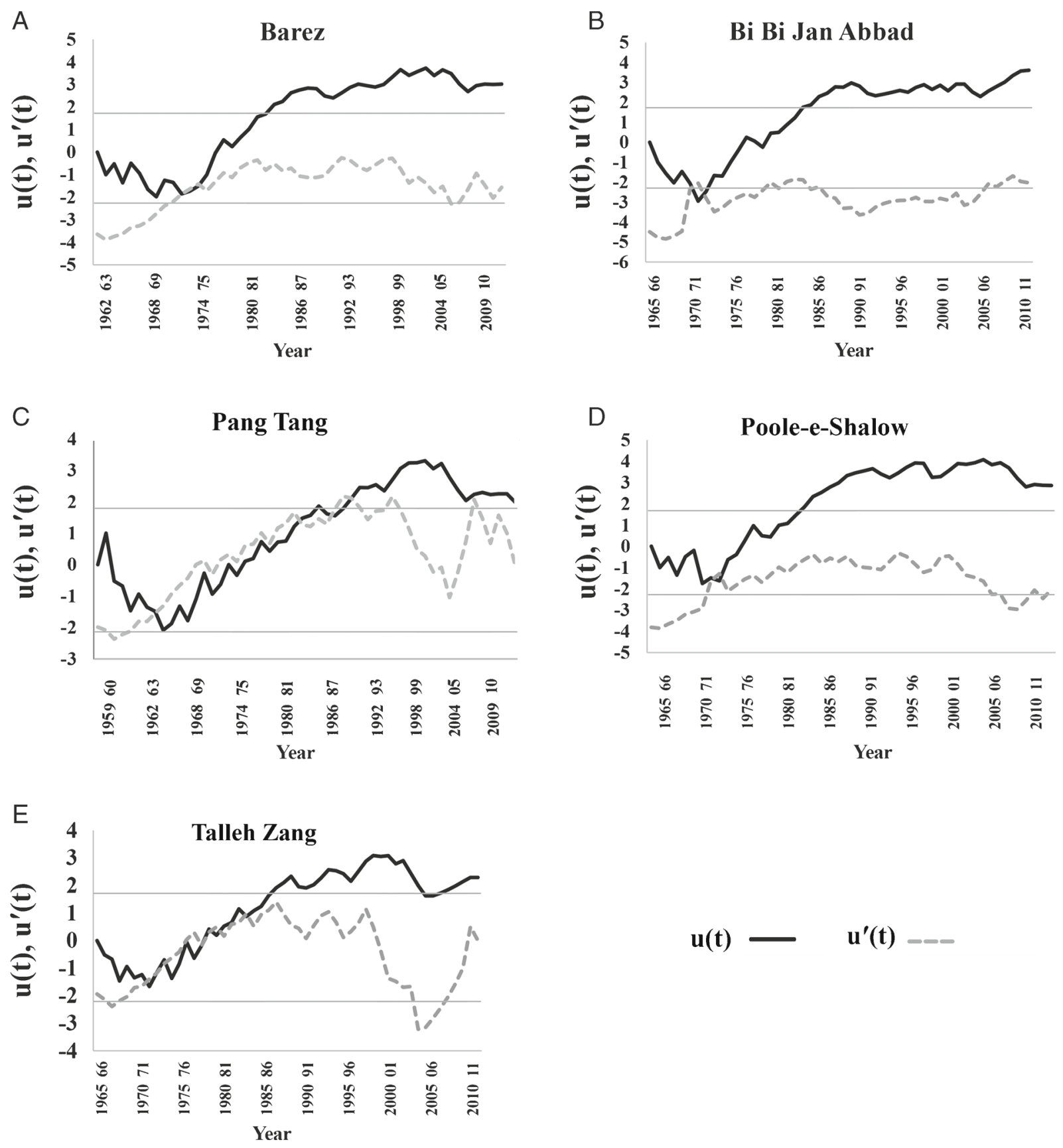

Figure 9. Graphical illustration of the series $u(t)$ and the backward series $u^{\prime}(t)$ of the SQ-MK test for the annual river discharge series at stations with significant trends.

discharge and precipitation with the exception of the October series were found to be significant at the significance level of 0.05 , whereas almost all of the positive correlations were found to be significant with the exception of June. Abghari et al. (2013) and Masih et al. (2011) found strong correlations between stream-flows and precipitation over the west of Iran. The strongest relationship (correlation coefficient of 0.684 ) was found between November area-averaged river discharge and precipitation. One of the interesting points about the correlation between area-average precipitation and river discharge is that the negative correlations were found in the dry months of the year when the mean precipitation is near zero (figure 10). In total, there is a close relationship between discharge and precipitation in most of the months. Discharge and precipitation had an insignificant increasing trend in most of the months in the study area. The variation of the area-averaged monthly river discharge and precipitation in the study period showed that most precipitation in the region occurs between December and January, but river discharge peak is observed 

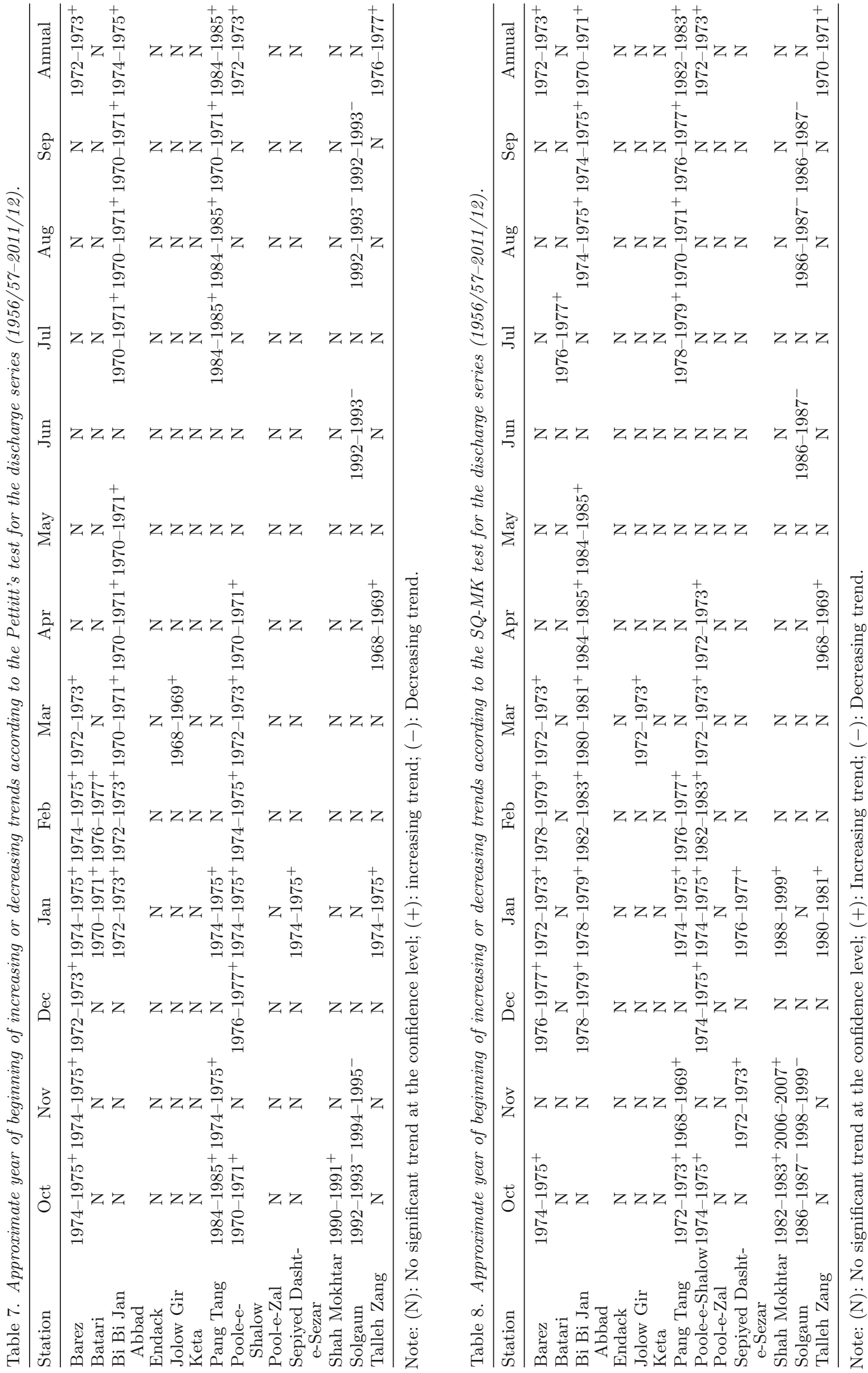
Table 9. Values of the statistic $Z$ of the Spearman's rho test for the annual and monthly discharge (1956/57-2011/12).

\begin{tabular}{|c|c|c|c|c|c|c|c|c|c|c|c|c|c|}
\hline Station & Oct & Nov & Dec & Jan & Feb & Mar & Apr & May & Jun & Jul & Aug & Sep & Annual \\
\hline 3arez & $0.32^{*}$ & $0.36^{*}$ & $0.41 *$ & $0.57^{*}$ & $0.41 *$ & $0.33^{*}$ & 0.24 & 0.21 & 0.23 & 0.18 & 0.23 & 0.05 & $0.43 *$ \\
\hline & & 01 & -0.17 & 0.2 & & & & & & & -003 & -0.03 & $0.32 *$ \\
\hline \multicolumn{14}{|l|}{ Bi Bi Jan } \\
\hline Abbad & 24 & $.33^{*}$ & 0.29 & $0.41^{*}$ & $0.44^{*}$ & $0.31^{*}$ & $0.46^{*}$ & $0.30 *$ & 0.27 & $0.30 *$ & 0.28 & 0.20 & $0.51 *$ \\
\hline Endack & 0.05 & 0.11 & 0.03 & 0.28 & 0.26 & 0.16 & & 0.08 & 0.05 & 0.08 & 0.01 & 0.27 & 0.29 \\
\hline Jolow Gir & -0.21 & -0.06 & -0.05 & 0.03 & -0.02 & 0.18 & .08 & -0.07 & -0.07 & -0.01 & -0.12 & -0.13 & 0.07 \\
\hline Keta & -0.07 & -0.01 & -0.03 & $0.17^{*}$ & 0.23 & 0.23 & 0.24 & 0.17 & 0.03 & 0.05 & 0.08 & -0.25 & 0.23 \\
\hline Pang Tang & $0.57^{*}$ & $0.43^{*}$ & 0.17 & $0.39 *$ & 0.26 & 0.18 & 0.15 & -0.05 & 0.06 & $0.44^{*}$ & $0.56 *$ & $0.63^{*}$ & $0.42 *$ \\
\hline \multicolumn{14}{|l|}{ Poole-e- } \\
\hline Shalow & 0.27 & 0.24 & 0.27 & 0.53 & $0.36^{*}$ & $0.39 *$ & $0.37 *$ & 0.24 & 0.23 & 0.13 & 0.14 & 0.16 & $0.40^{*}$ \\
\hline Pool-e-Zal & 0.10 & 0.24 & 0.31 & 0.22 & -0.09 & -0.25 & -0.08 & -0.07 & -0.18 & -0.25 & -0.09 & -0.01 & -0.01 \\
\hline \multicolumn{14}{|l|}{ Sepiyed } \\
\hline Dasht-e-Sezar & & & & & & & & 0.03 & -0.02 & & -0.09 & 0.01 & 0.19 \\
\hline Shah Mokhtar & $0.37 *$ & 0.35 & 0.30 & $0.37^{*}$ & $0.37^{*}$ & 0.19 & 0.05 & -0.01 & 0.01 & 0.09 & 0.17 & 0.31 & 0.28 \\
\hline Solgaun & $-0.41 *$ & -0.38 & -0.32 & $-0.42^{*}$ & -0.18 & 0.01 & -0.24 & 0.31 & $-0.38 *$ & -0.30 & $-0.42^{*}$ & $-0.47^{*}$ & -0.21 \\
\hline TallehZang & 0.12 & 0.17 & 0.23 & $0.30 *$ & 0.15 & 0.24 & $0.30^{*}$ & 0.20 & 0.19 & 0.18 & 0.20 & 0.20 & $0.37^{*}$ \\
\hline
\end{tabular}

(*)Trends statistically significant at the $95 \%$ confident level.

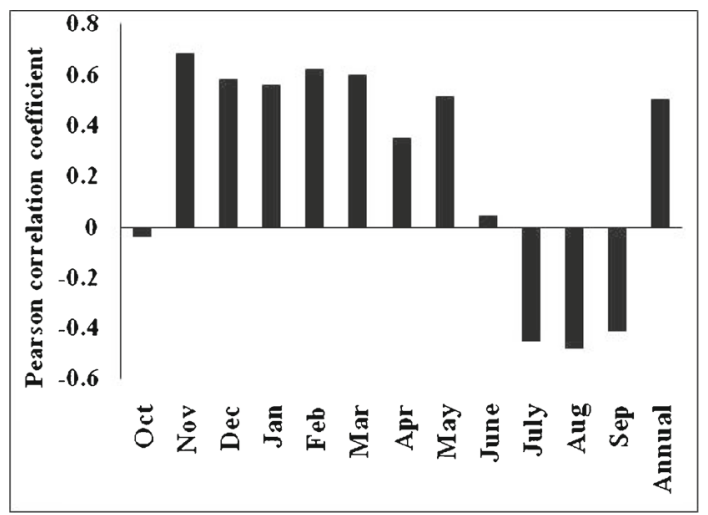

Figure 10. Pearson correlation coefficient between areaaveraged precipitation and river discharge.

in April due to snowmelt contribution (figure 11). The observed increasing trend in temperature series (Zarenistanak et al. 2014a, b) over the study area might affect the snow melt causing increased river discharge in October through April series. In mountain basins such as our study region, snow is the main source of river flows so, change in snow cover can have an influence on the discharge of the rivers. Snow cover will decrease according to climate model outputs at the end of the 21st century in the southwest part of Iran (Zarenistanak 2014). This decrease of snow cover can negatively influence the river discharges in the region in the future.

\section{Conclusions}

This paper presents trends computed from a 56year period of annual and monthly precipitation

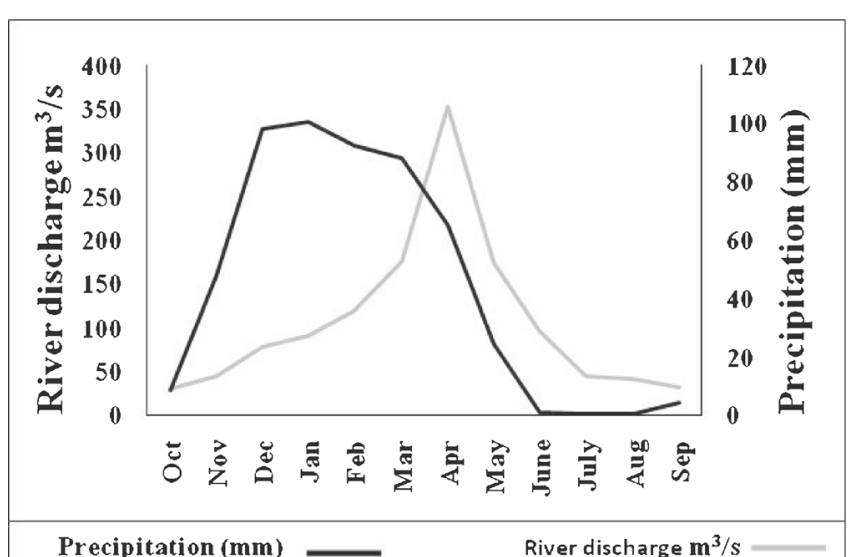

Figure 11. Area-averaged monthly river discharge and precipitation over the study period 1956/57-2011/12.

and river discharge data obtained from 17 rain gauge and 13 hydrometric stations in the southwest of Iran. Five trend tests, viz., MK-test, Spearman's rank test, Pettitt's test, SQ-MK test, and Sen's slope estimator were used for the trend analysis. Analysis of the serial correlation in the time series showed that the majority of the considered series did not reveal a significant lag1 correlation coefficient, except for the October discharge and April precipitation series. Most of the previous studies in the west of Iran reported decreasing trends in the precipitation and river discharge time series. However, our results indicated no significant trend in the annual and monthly precipitation series, but in the discharge series most of the stations showed an increasing trend during both the annual and October through April series. Significant increasing trends of 14.03, 12.21, 6.65, 15.57 , and $20.49 \mathrm{~m}^{3} / \mathrm{s}$ per decade were found in the 
annual river discharge series of Barez, $\mathrm{Bi} \mathrm{Bi}$ Jan Abbad, Pang Tang, Poole-e-Shalow, and Talleh Zang stations, respectively. Significant increasing discharge trends were obtained at seven and four stations in January and February, respectively. In general, the significant trends in monthly discharge occurred mostly during the autumn and winter seasons. One of the reasons for the observed significant trends in the river discharge time series during the autumn and winter seasons could be increasing trends in air temperature and subsequent effects on snow melt.

The results of the Pettitt and SQ-MK tests for discharge data showed that most of the significant mutation points began in the 1970s. Area-averaged river discharge had a significant positive correlation with area-averaged precipitation for annual level and all months except for October, July, August, and September when a negative significant correlation was found.

The industrialization as well as the increases in agricultural development and a growing population in the region will increase the demand for fresh water in the coming decades. Therefore, the studies on the effects of climate changes on hydro-meteorological variables effective on water resource such as temperature, precipitation, river flow, evaporation, and snow cover can be interesting and useful for water resource management and planning. In future studies, it would be interesting to compare the trends found in our study with the temporal trends in other meteorological and hydrological variables.

\section{Acknowledgements}

The authors are thankful to the Islamic Republic of Iran Meteorological Organization (IRIMO) and Water Resources Management Organization of the Ministry of Energy, Islamic Republic of Iran for providing observed data. They also thank the anonymous reviewers for their comments and suggestions which helped in improving the paper.

\section{References}

Abghari H A, Tabari H and Hosseinzadeh Talaee P 2013 River flow trends in the west of Iran during the past 40 years: Impact of precipitation variability; Global Planet. Change 101 52-60.

Arami A, Faridgiglo B and Esmaliouri A 2013 Assessment of variations in river discharge and sediment at some stations of Gorgan-Roud River, Golestan Province, Iran; Int. J. Agri. Crop Sci. 5(12) 1351-1357.

Boroujerdy P 2008 The analysis of precipitation variation and quantiles in Iran; 3rd IASME/WSEAS, Int. Conf. on Energy and Environment, University of Cambridge, England.
Cao J, Qin D, Kang E and Li Y 2006 River discharge changes in the Qinghai-Tibet Plateau; Chinese Sci. Bull. 51(5) 594-600.

Delju A H, Ceylan A, Piguet E and Rebetez M 2013 Observed climate variability and change in Urmia Lake Basin, Iran; Theor. Appl. Climatol. 111 285-296.

Dhorde A and Zarenistanak M 2013 Three-way approach to test data homogeneity: An analysis of temperature and precipitation series over southwestern Islamic Republic of Iran; J. Ind. Geophys. Union 17(3) 233-242.

Dhorde A, Zarenistanak M, Kripalani R H and Preethi B 2014 Precipitation analysis over southwest Iran: Trends and projections; Meteorol. Atmos. Phys., doi: 10.1007/s00703-014-0313-9.

Ding Y, Ye B, Han T, Shen Y and Liu S 2007 Regional difference of annual precipitation and discharge variation over west China during the last 50 years; Sci. China Series Earth Sci. 50(6) 936-945.

Du J, He F, Zhang Z and Shi P 2011 Precipitation change and human impacts on hydrologic variables in Zhengshui River Basin, China; Stoch. Environ. Res. Risk Assess. 25(7) 1013-1025.

Feng X, Zhang G and Yin X 2011 Hydrological responses to climate change in Nenjiang River Basin, northeastern China; Water Resour. Manag. 25 677-689.

Jiang T, Su B and Hartmann H 2007a Temporal and spatial trends of precipitation and river flow in the Yangtze River Basin, 1961-2000; Geomorphology 85 143-154.

Jiang Y, Zhou C and Cheng W 2007b Streamflow trends and hydrological response to climatic change in Tarim headwater basin; J. Geogr. Sci. 17(1) 51-61.

Kahya E and Kalayci S 2004 Trend analysis of streamflow in Turkey; J. Hydrol. 289 128-144.

Kang H M and Yusof F 2012 Homogeneity tests on daily rainfall series in peninsular Malaysia; Int. J. Contemp. Math. Sci. 7(1) 9-22.

Kohler M A 1949 Double-mass analysis for testing the consistency of records and for making adjustments; Bull. Am. Meteor. Soc. 30 188-189.

Kriauciuniene J, Meilutyte-Barauskiene D, Reihan A, Koltsova T, Lizuma L and Sarauskiene D 2012 Variability in temperature, precipitation and river discharge in the Baltic states; Boreal Env. Res. 17 150-162.

Marofi S and Tabari H 2012 Detection of Maroon River flow trends using parametric and non-parametric methods; Geogr. Res. 101(2) 125-146 (in Persian).

Masih I, Uhlenbrook S, Maskey S and Smakhtin V 2011 Streamflow trends and climate linkages in the Zagros Mountains, Iran; Clim. Change 104(2) 317-338.

Moazed H, Salarijazi M, Moradzadeh M and Soleymani S 2012 Changes in rainfall characteristics in southwestern Iran; African J. Agr. Res. 7(18) 2835-2843.

Modarres R and da Silva V 2007 Rainfall trends in arid and semi-arid regions of Iran; J. Arid Environ. $70344-$ 355.

Mousavi S F 2005 Agricultural drought management in Iran; Water Conservation, Reuse, and Recycling: Proceedings of an Iranian-American Workshop, pp. 106-113.

Naddafi K, Honari H and Ahmadi M 2007 Water quality trend analysis for the Karoon River in Iran; Environ. Monit. Assess. 134(1-3) 305-312.

Niazi F, Mofid H and Fazel Modares N 2014 Trend analysis of temporal changes of discharge and water quality parameters of Ajichay River in four recent decades; Water Qual. Expo. Health 6 89-95.

Oki T and Kanae S 2006 Global hydrological cycles and world water resources; Science 313 1068-1072.

Partal T and Kahya E 2006 Trend analysis in Turkish precipitation data; Hydrol. Process. 20 2011-2026. 
Pavelsky T M and Smith L C 2006 Intercomparison of four global precipitation data sets and their correlation with increased Eurasian river discharge to the Arctic Ocean; J. Geophys. Res. Atmos., doi: 10.1029/2006JD007230.

Pettitt A N 1979 A non-parametric approach to the change point problem; Appl. Statist. 28(2) 126-135.

Ramazanipour M 2011 Test and trend analysis of precipitation and discharge in the north of Iran (case study: Polroud basin); World Appl. Sci. J. 14(9) 1286-1290.

Raziei T 2008 Investigation of annual precipitation trends in homogeneous precipitation sub-divisions of western Iran; BALWOIS (2008)-Ohrid Republic of Macedonia.

Sadeghi A R, Kamgar-Haghighi A A, Sepaskahaha A R, Khalili D and Zand-Parsa S 2002 Regional classification for dry land agriculture in southern Iran; J. Arid Environ. $50333-341$.

Sen P K 1968 Estimates of the regression coefficient based on Kendall's tau; J. Am. Stat. Assoc. 63(324) 1379-1389.

Shifteh Somee B, Ezani A and Tabari H 2012 Spatiotemporal trends and change point of precipitation in Iran; Atmos. Res. 113 1-12.

Smadi M M and Zghoul A 2006 A sudden change in rainfall characteristics in Amman, Jordan during the mid 1950's; Am. J. Environ. Sci. 2(3) 84-91.

Sneyers S 1990 On the statistical analysis of series of observations; Technical note no. 143, WMO No. 725 415, Secretariat of the World Meteorological Organization, Geneva, 192p.

Soltani S, Saboohi R and Yaghmaei L 2011 Rainfall and rainy days trend in Iran; Climate Change 110 187-213.

Tabari H and Hosseinzadeh Talaee P 2011a Temporal variability of precipitation over Iran: 1966-2005; J. Hydrol. 396(3-4) 313-320.

Tabari H and Hosseinzadeh Talaee P 2011b Analysis of trends in temperature data in arid and semi arid-regions of Iran; Global Planet. Change 79 1-10.

Tabari H and Aghajanloo M B 2013 Temporal pattern of aridity index in Iran with considering precipitation and evapotranspiration trends; Int. J. Climatol. 33(2) 396409.

Tabari H, Shifteh Somee B and Rezaeian Z M 2011a Testing for long-term trends in climatic variables in Iran; Atmos. Res. 100 132-140.
Tabari H, Hosseinzadeh Talaee P, Ezani A and Shifteh Somee B 2011b Shift changes and monotonic trends in autocorrelated temperature series over Iran; Theor. Appl. Climatol. 109 95-108.

Tarhule A and Woo M 1998 Changes in rainfall characteristics in northern Nigeria; Int. J. Climatol. 18 1261-1271.

von Storch H 1995 Misuses of statistical analysis in climate research; In: Analysis of climate variability: Applications of statistical techniques (eds) Storch HV and Navarra A, Springer, Berlin, pp. 11-26.

Wijngaard J B, Klein Tank M and Konnen G P 2003 Homogeneity of 20th century European daily temperature and precipitation series; Int. J. Climatol. 23 679-692.

Xiong L and Guo S 2004 Trend test and change-point detection for the annual discharge series of the Yangtze River at the Yichang hydrological station; Hydrol. Sci. J. 49(1) 99-112.

$\mathrm{Xu} \mathrm{K}$, Milliman J D and Xu H 2010 Temporal trend of precipitation and runoff in major Chinese Rivers since 1951; Global Planet. Change 73(3-4) 219-223.

Yang S L, Gao A, Helenmary M, Hotz J, Zhu S, Dai B and Li M 2005 Trends in annual discharge from the Yangtze River to the sea (1865-2004); Hydrol. Sci. J 50(5) 825-836.

Yang S L, Zhang J and Xu X J 2007 Influence of the three Gorges Dam on downstream delivery of sediment and its environmental implications, Yangtze River; Geophys. Res. Lett., doi: 10.1029/2007GL029472.

Yenigun K, Gumus V and Bulut H 2008 Trends in streamflow of the Euphrates basin, Turkey; Water Manag. 161 189-198.

Zarenistanak M, Dhorde A and Kripalani R H 2014a Temperature analysis over southwest Iran: Trends and projections; Theor. Appl. Climatol. 116 103-117.

Zarenistanak M, Dhorde A and Kripalani R H 2014b Trend analysis and change point detection of annual and seasonal precipitation and temperature series over southwest Iran; J. Earth Syst. Sci 123 281-295.

Zarenistanak M 2008 Trends analysis in precipitation data over north of Iran; Journal of Islamic Azad University, Central Tehran Branch 22 1-15 (in Persian).

Zarenistanak M 2014 Investigation of climatic trends and snow cover change over southwestern Islamic Republic of Iran since 1960; Ph.D. thesis, Department of Geography, University of Pune, Pune, India. 